\title{
Comparative analysis of Maximum Power Point Tracking Algorithms for Photovoltaic Applications
}

\author{
BHARATHI SANKAR AMMAIYAPPAN, R. SEYEZHAI \\ Assistant Professor, School of Electronics Engineering, \\ VIT University Chennai Campus, Chennai, INDIA \\ Associate Professor, Department of Electrical and Electronics Engineering, \\ Renewable Energy Conversion Lab, SSN College of Engineering, Chennai, INDIA.
}

\begin{abstract}
Currently, photovoltaic system has gained importance in electrical power generation system, since it is a clean and renewable energy source. An important characteristic of photovoltaic panels is that the available maximum power is provided only in a single operating point called maximum power point. But the position of maximum power point is not fixed and it moves according to the varying irradiance, varying temperature and the load. This requires a mechanism called maximum power point tracking (MPPT) so that maximum power is obtained effectively. In the literature, many classical methods have been developed and implemented to track the maximum power point. The main objective of this paper is to study and analyze the classical techniques such as Perturb and Observe (P\&O), Incremental Conductance (IC) and Fuzzy Logic Control (FLC) algorithms and propose an Adaptive Fuzzy Logic Control (AFLC) for MPPT. The performance of AFLC is compared with the conventional MPPT techniques for varying irradiance. The significance of these methods are studied by implementing the algorithm in MATLAB. The experimental results show the effectiveness and feasibility of the proposed method and the results are verified. The results reveal that the adaptive FLC can quickly track change of MPP for various light intensity and delivers higher power compared to the classical algorithms.
\end{abstract}

Keywords: Photovoltaic system, Maximum Power Point Tracking, Adaptive Fuzzy Logic Control, Perturb and Observe (P\&O), Incremental Conductance (IC) and Fuzzy Logic Control (FLC).

Received: February 4, 2020. Revised: August 12, 2020. Accepted:September 7, 2020. Published: September 15, 2020

\section{Introduction}

There is an increase in global energy demand day by day. The best source of energy that can be chosen is renewable energy. Solar energy is available in abundance. Hence to meet the growing demand, solar energy is converted to electrical energy by using Photovoltaic (PV) systems. The PV systems have non-linear characteristics and their energy conversion efficiency is very low. Hence, Maximum Power Point Tracking (MPPT) is used to increase the efficiency of the system. It is used to ensure that maximum available energy is extracted under varying environmental conditions such as solar irradiation, temperature, load, etc. This further ensures that the available generating systems are used efficiently with additional cost. Various algorithms have been implemented to design MPPT based PV system [1]-[4].This paper gives a comparative study of the existing algorithms and proposes an adaptive fuzzy logic to implement MPPT. The implementation of MPPT techniques began in 1970's. These techniques differ in efficiency, complexity, cost, power generated and so on. Before choosing an appropriate technique to design a PV system, it is necessary to study the characteristics of the available methods. This is important as the effective utilization of the available PV infrastructure is required. This paper presents the study of the classical techniques on the basis of their characteristics. The methods implemented and considered for comparison are: Perturb and Observe (P\&O), Incremental Conductance (IC) and Fuzzy Logic Control (FLC) and Adaptive Fuzzy Logic Control (AFLC). These techniques are studied and investigated in MATLAB. The simulation results are verified experimentally. The results show that AFLC provides a higher peak power compared to other MPPTs. A concluding report has been presented to find out the suitable technique for extracting maximum power from PV. 


\section{Numerical modeling of solar cell}

The solar cells are made of semiconductor material with a p-n junction fabricated in a thin wafer layer. These cells, when exposed to light, a photo current proportional to the solar radiation is generated, if the photon energy is greater than the band gap. In the dark, the I-V characteristics of a solar cell have an exponential characteristic similar to that of a diode [5].In order to maximize the output power from a PV cell with the help of MPPT control, the modeling of PV cell is necessary[6]. The ideal equivalent circuit of a solar cell is a current source in parallel with a single-diode. The configuration of the solar cell with single-diode model is shown in Figure 1.

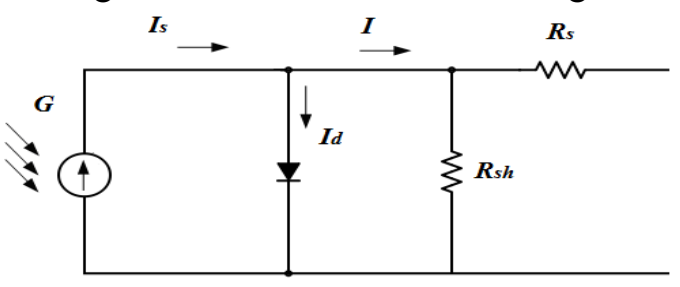

Figure 1. Model of a solar cell.

In Figure 1, $G$ denotes the solar radiance, $I_{s}$ represents the photo generated current, $I_{d}$ is the diode current, $I$ is the output current, and $V$ is the terminal voltage. The I-V characteristics of the ideal solar cell with single diode is given by: Equation (1-4)

$I=I_{S}-I_{o}\left[e^{\frac{q V}{m k T}}-1\right]$

(1)

Where $I_{o}$ is the diode reverse bias saturation current, $q$ is the electron charge, $m$ is the diode ideality factor, $k$ is the Boltzmann's constant, and $T$ is the cell temperature. A solar cell is characterized by the short circuit current $I_{s c}$, the open circuit voltage $V_{o c}$, and the diode ideality factor $m$. For the same irradiance and $p$ - $n$ junction temperature conditions, the short circuit current $\mathrm{I}_{\mathrm{sc}}$ is the maximum value of the current generated by the cell. It is given by:

$I_{s c}=I=I_{s}$ For $V=0$

(2)

For the same irradiance and $p-n$ junction temperature conditions, the open circuit voltage
$V_{o c}$ is the highest value of the voltage that appears at the cell terminals. It is given by:

$V=V_{o c}=\frac{m k T}{q} \ln \left(I+\frac{I_{S c}}{I_{o}}\right) \quad$ For $I=0$

(3)

The output power is given by:

$P=V\left[I_{S C}-I_{o}\left[e^{\frac{q V}{m k T}}-1\right]\right]$

Table 1 shows that electrical characteristics of PV array, extracted from the manufacturer data which is used for the modeling of PV in MAT LAB Simulink block sets.

Table 1. Specification of PV Panel.

\begin{tabular}{|l|l|}
\hline $\mathbf{V}_{\text {oc }}$ & $31.16 \mathrm{~V}$ \\
\hline $\mathbf{I}_{\text {sc }}$ & $8.57 \mathrm{~A}$ \\
\hline $\mathbf{P}_{\max }$ & $250 \mathrm{~W}$ \\
\hline Insolation W/m & \\
\hline System efficiency & $1000 \mathrm{~W} / \mathrm{m}^{2}$ \\
\hline
\end{tabular}

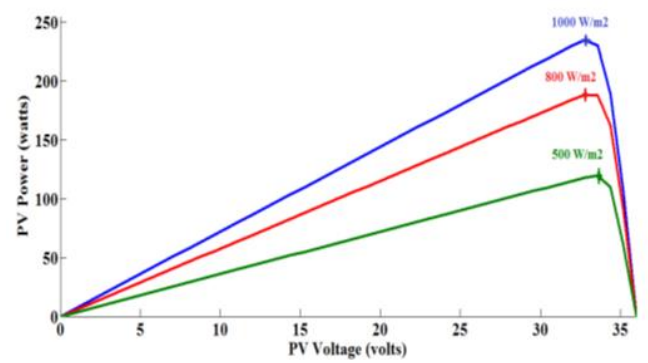

Figure 2. P-V characteristics for variable irradiance.

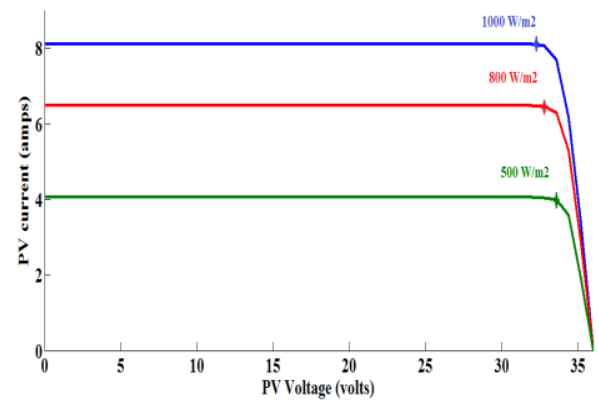

Figure 3. I-V characteristics for variable irradiance. 
The PV and VI characteristics for varying irradiation at constant temperature is shown in Figures $2 \& 3$. When the irradiation increases, the output current increases and the output voltage also increases. This results in net increase in output power with increase in irradiation at constant temperature.

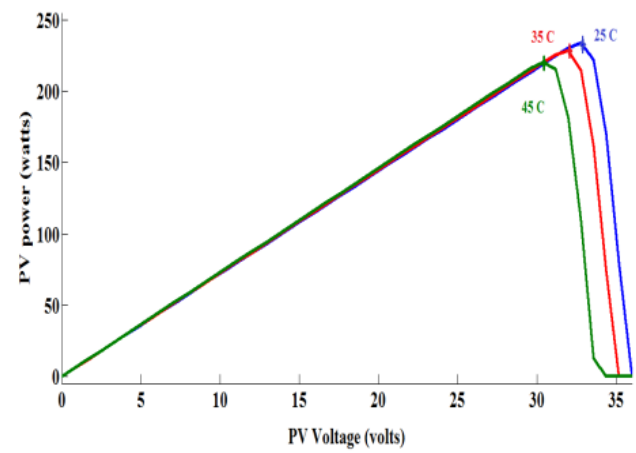

Figure 4 P-V characteristics for variable temperature.

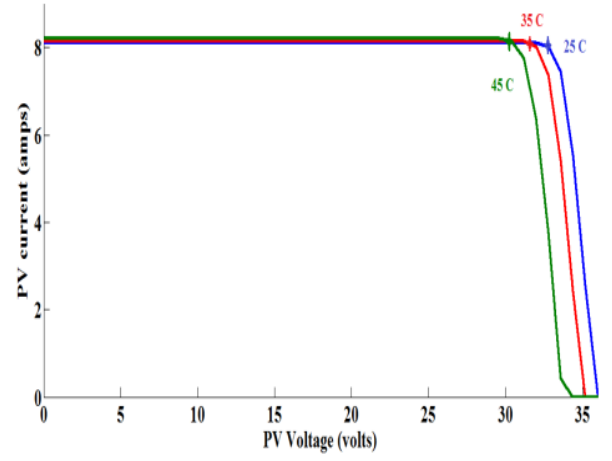

Figure 5. I-V characteristics for variable temperature.

The PV power and current with varying temperature at constant irradiation is shown in Figures $4 \& 5$. When the operating temperature increases, the output current increases marginally but the output voltage decreases drastically resulting in net reduction in output power with rise in temperature.

\section{Perturb and Observe (P \& O) method}

$\mathrm{P} \& \mathrm{O}$ is an iterative method. It senses the panel operating voltage periodically and compares the PV output power with that of the previous power; the resulting change in power $(\Delta \mathrm{P} \quad \mathrm{PV})$ is measured. If $\Delta \mathrm{P}_{\mathrm{PV}}$ is positive, the perturbation of the operating voltage should be in the same direction of the increment. However, if it is negative, the system operating point obtained moves away from the MPPT and the operating voltage should be in the opposite direction of the increment, perturbation should be reversed to move back towards the MPP. This process continues till $\mathrm{dP}_{\mathrm{PV}} / \mathrm{dV}_{\mathrm{PV}}=0$ regardless of the irradiance and PV module's terminal voltage [7,8]. A scheme of the algorithm is shown in Figure 6, according to which PV module output voltage $V_{P V}$ and output current $I_{P V}$ are sensed. Then power is calculated $\mathrm{P}(\mathrm{n})$ and compared with the power measured at the previous sample $\mathrm{P}(\mathrm{n}$ $1)$ in order to calculate $\Delta P$. Then according to the sign of $\Delta \mathrm{P}$ and $\Delta \mathrm{V}, \mathrm{MPP}$ is tracked.

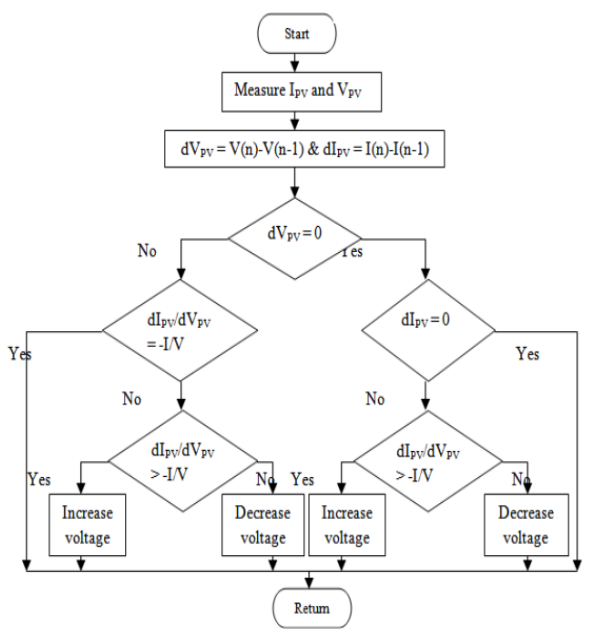

Figure 6. Flowchart of Perturb and observe MPPT method.

\section{Incremental conductance method}

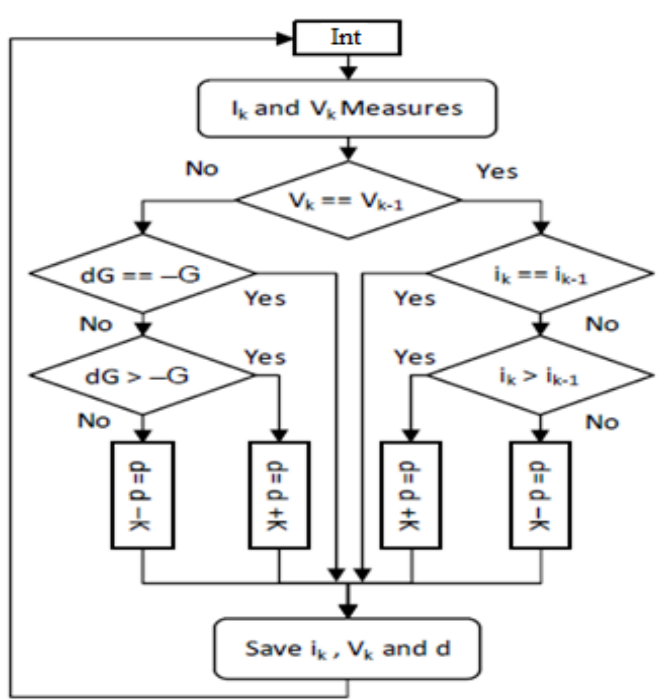

Figure 7. Flowchart of Incremental conductance method. 
This method uses the photovoltaic panel incremental conductance $\mathrm{dI} / \mathrm{dV}$ to compute the sign of $\mathrm{dP} / \mathrm{dV}$. When $\mathrm{dI} / \mathrm{dV}$ is equal and opposite to the value of $\mathrm{I} / \mathrm{V}$ (where $\mathrm{dP} / \mathrm{dV}=0$ ) the incremental conductance algorithm knows that the maximum power point tracking control is reached and thus it terminates and returns the corresponding value of operating voltage for maximum power point. Flow chart of incremental conductance method is shown in Figure 7. Moreover, this method tracks rapidly changing solar irradiation conditions more accurately than conventional method $[9,10]$. One complexity in this method is that it requires many sensors to operate and hence is economically less effective. Equations governing the proposed algorithm are as follows: Equation (5-11)

$P=V * I$

$\frac{d P}{d V}=\frac{d(V * I)}{d V}$

$\frac{d P}{d V}=I *\left(\frac{d V}{d V}\right)+V *\left(\frac{d I}{d V}\right)$

(7)

$\frac{d P}{d V}=I+V *\left(\frac{d I}{d V}\right)$

When the MPPT is reached the slope

$\frac{d P}{d V}=0$

(9)

$I+V *\left(\frac{d I}{d V}\right)=0$

(10)

$\frac{d I}{d V}=-\frac{I}{V}$

\section{Fuzzy logic control based MPPT}

Several methods of tracking the optimal point of operation have been discussed in the literature but the approach of artificial intelligence in the case of fuzzy logic is implemented to improve the controller performance and the pursuit of maximum power point by simulation and modeling of a controller based on fuzzy logic control system. Block diagram of fuzzy logic control MPPT based photovoltaic power generation system is shown in Figure 8 [11-14]. The fuzzy theory based on fuzzy set and fuzzy algorithm provides a general method of expressing linguistic rules so that they may be processed quickly. The advantage of the fuzzy logic control is that it does not strictly need any mathematical model of the system. Hence, many complex systems can be controlled without knowing the exact mathematical model of the system. In addition, fuzzy logic simplifies the design when dealing with nonlinearities in systems[15,16][24,25].Equation (12-14)

Fuzzy controller design includes the following elements:

- Determine the fuzzy controller input variables and output variables.

- Design the control rules of fuzzy controller.

- Establish fuzzification and Defuzzification method.

- Select the domain of fuzzy controller input and output variables as well as determine the parameters.

- Prepare the application of fuzzy control algorithm.

- Choose a reasonable sampling time of fuzzy control.

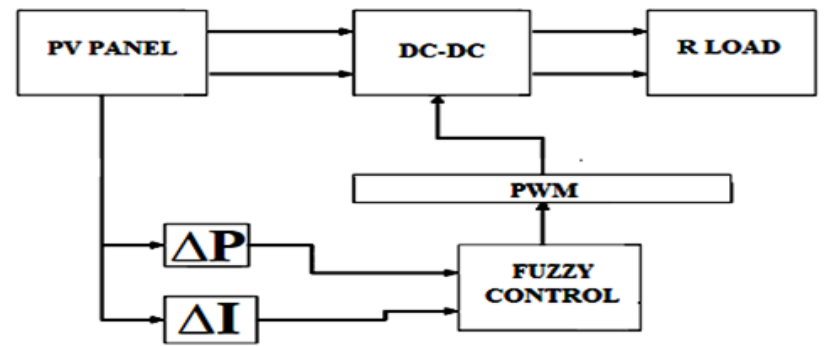

Figure 8. Block diagram of fuzzy logic control based photovoltaic power generation system.

The inputs of the FLC are:

$\Delta P=I(k)-P(k-1)$

(12)

$\Delta I=I(k)-I(k-1)$

(13)

and the output equation is:

$\Delta D=D(k)-D(k-1)$ 
Table 2. Fuzzy logic rules.

\begin{tabular}{|c|c|c|c|c|}
\hline e/de & NB & NS & PS & PB \\
\hline NB & PB & PB & NB & NB \\
\hline NS & PS & PS & NS & NS \\
\hline PS & NS & NS & PS & PS \\
\hline PB & NB & NB & PB & PB \\
\hline
\end{tabular}

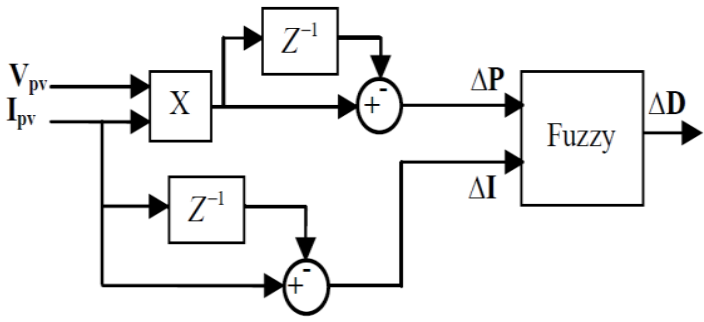

Figure 9. Block diagram of the FLC based MPPT.

Where $\Delta \mathrm{P}$ is the $\mathrm{PV}$ array output power change, $\Delta \mathrm{I}$ is the array output current change, and $\Delta \mathrm{D}$ is the boost converter duty cycle change. The variable inputs and outputs are divided into four fuzzy subsets: PB (Positive Big), PS (Positive Small), NB (Negative Big) and NS (Negative Small). Therefore, the fuzzy rule algorithm requires 16 fuzzy control rules; these rules are based on the regulation of hill climbing algorithm, fuzzy rules are shown in Table 2. To operate the fuzzy combination, Mamdani's method with Max-Min is used. Figure 9 shows the FLC based MPPT.

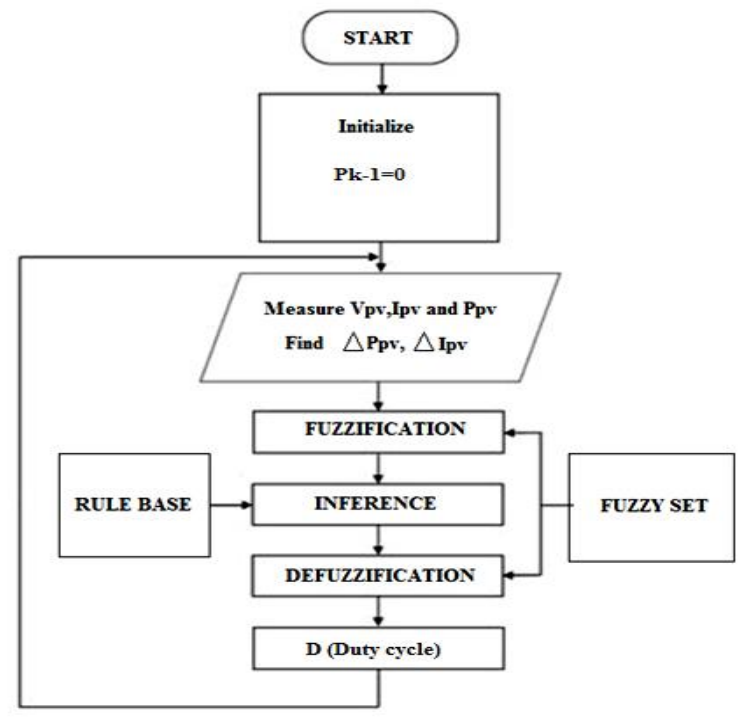

Figure 10. Flow chart of the FLC based MPPT.

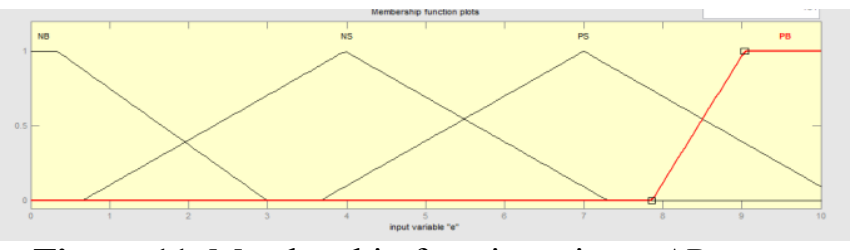

Figure 11. Membership functions: input $\Delta \mathrm{P}$.

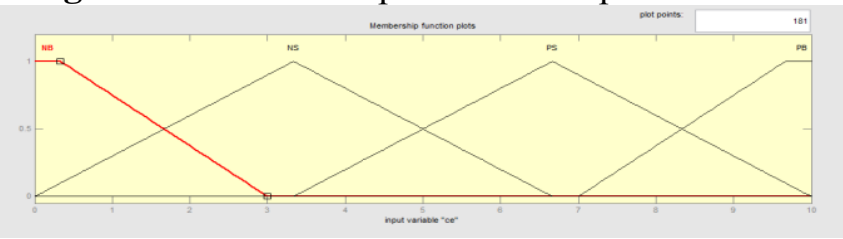

Figure 12. Membership functions: input $\Delta \mathrm{I}$.

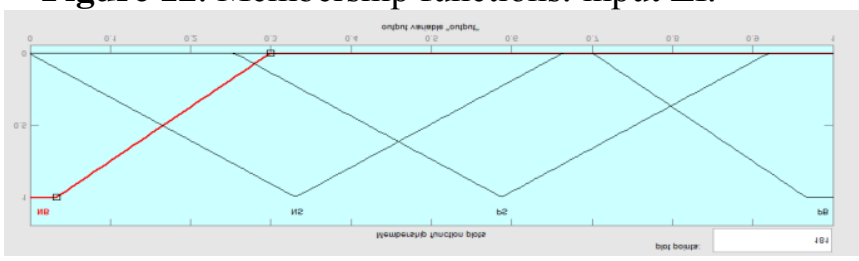

Figure 13. Membership functions: output $\Delta \mathrm{D}$. From the behavior of the controller inputs and output, the shapes and fuzzy subset partitions of the membership function of both input and output are shown in Figure 11 to Figure 13. Flow chart of the FLC based MPPT is shown in Figure 10. The centre of area algorithm (COA) is used in the defuzzification stage to convert the fuzzy subset duty cycle changes to real numbers. Equation (15)

$\Delta D=\frac{\sum_{i}^{n} \mu\left(D_{i}\right) D_{i}}{\sum_{i}^{n} \mu\left(D_{i}\right)}$

(15)

Where $\Delta \mathrm{D}$ is the fuzzy controller output and $\mathrm{Di}$ is the centre of Max-Min composition at the output membership function.

\section{Proposed Adaptive Fuzzy Logic Controller (AFLC) MPPT technique}

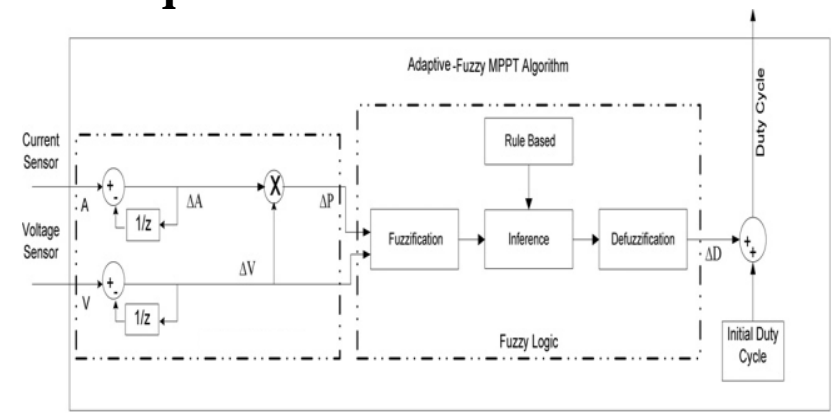

Figure 14. Structure of adaptive fuzzy logic controller. 
In this section, the AFLC controller for MPPT is discussed, and the goal is to maximize the output power of PV [17-20]. Fuzzy logic control MPPT with fixed parameters are inadequate in applications where the operating condition changes in a wide range and available expert knowledge is not reliable. To make the controller less dependent on expert knowledge, the adaptive fuzzy logic control is proposed. The proposed AFLC is improved from scaling FLC, and it is mainly to adjust the duty-cycle of the defuzzification of FLC for external variations and solar irradiance. It can re-adjust fuzzy parameter to obtain optimum performance. According to voltage $\left(\mathrm{V}_{\mathrm{PV}}\right)$ and current $\left(\mathrm{I}_{\mathrm{PV}}\right)$ of PV module, the duty cycle $\mathrm{D}$ will be determined through the AFLC controller in order to realize MPPT[21,22]. The structure of the proposed AFLC controller is shown in Figure 14 and it contains two parts: (i) fuzzy logic control and (ii) adaptive mechanism.

\section{Adaptive mechanism}

The purpose of the adaptive mechanism is to modify the duty cycle of the defuzzification of FLC, so it makes the PV system to provide a better response time and a higher output power[23]. The adaptive mechanism comprises three parts which is discussed as follows:

First, in order to eliminate the high-frequency noise, we adopt the moving average filter to compute $\mathrm{P}_{\mathrm{PV}}$ as: Equation (16-18)

$$
\mathrm{P}_{\mathrm{pv}}(\mathrm{n})=\left[\mathrm{P}_{\mathrm{pv}}(\mathrm{n}-1)+\mathrm{P}_{\mathrm{pv}}(\mathrm{n}-2)\right] / 2
$$

The moving average filter is a good way to estimate the local trend of the signal with possible high-frequency disturbances/noise. The basic idea is by using the average computation of values within a moving window to estimate the trend in the change of the signal. The quality of trend estimation depends on the number of values within a window. Similarly, the sunlight intensity affects the current $\mathrm{I}_{\mathrm{PV}}$ of $\mathrm{PV}$ module, so this method is used to estimate the trend of $I_{P V}$ as:

$$
\mathrm{I}_{\mathrm{pv}}(\mathrm{n})=\left[\mathrm{I}_{\mathrm{pv}}(\mathrm{n}-1)+\mathrm{I}_{\mathrm{pv}}(\mathrm{n}-2)\right] / 2
$$

Based on $\mathrm{P}_{\mathrm{PV}}(\mathrm{n})$ and $\mathrm{I}_{\mathrm{PV}}(\mathrm{n})$, plus comparing with the previous $P_{P V}(n-1)$ and $\operatorname{IPV}_{\mathrm{PV}}(\mathrm{n}-1)$, their differences can be computed. The differences of $\mathrm{P}_{\mathrm{PV}}$ and $\mathrm{I}_{\mathrm{PV}}$ can be either positive or negative. Thus, it can be summarized as four trends, and going a step further, four rules for adaptive mechanism can be suggested as shown in Table 3.

\begin{tabular}{|c|c|c|c|c|}
\hline Rule & $\begin{array}{l}{\left[P_{p v}(n)-\right.} \\
P_{p v}(n- \\
1)]>0\end{array}$ & $\begin{array}{l}{\left[\mathrm{I}_{\mathrm{pv}}(\mathrm{n})\right.} \\
-\mathrm{I}_{\mathrm{pv}}(\mathrm{n}- \\
1)]>0\end{array}$ & $\begin{array}{l}\text { Duty } \\
\text { cycle }\end{array}$ & $\begin{array}{l}\text { Select } \\
\text { of } \Delta K\end{array}$ \\
\hline 1 & True & True & \multirow{2}{*}{$\begin{array}{c}\text { decrease } \\
\text { a } \\
\text { little }\end{array}$} & \multirow[t]{2}{*}{$\mathrm{K}_{1}$} \\
\hline 2 & False & False & & \\
\hline 3 & True & False & \multirow{2}{*}{$\begin{array}{c}\text { Decrease } \\
\text { a } \\
\text { Lot }\end{array}$} & \multirow[t]{2}{*}{$\mathrm{K}_{2}$} \\
\hline 4 & False & True & & \\
\hline
\end{tabular}

Table 3. Adaptive mechanism of AFLC.

The rules are explained in detail as follows:

Rule 1 and Rule 2: A fixed parameter is inadequate in applications when the operating conditions change, and it is not reliable. Thus, the duty cycle can be modified by rule 1 and rule 2 , and then the adaptive value $\Delta K$ is assigned to $\mathrm{K}_{1}$ $=-0.25$. Because $\Delta K$ is a smaller negative value now, the duty cycle will be modified to decrease a little.

Rule 3 and Rule 4: The duty cycle can be modified by rule 3 and rule 4 , and then the adaptive value $\Delta K$ is assigned to $\mathrm{K}_{2}=-0.3$. Because $\Delta K$ is a bigger negative value now, the duty cycle will be modified to decrease a lot.

To combine this adaptive value $\Delta K$ and $\mathrm{V}_{\mathrm{c}}$ from defuzzification, the duty-cycle control voltage $\Delta V_{c}$ can be obtained as:

$\Delta V_{\mathrm{C}}=\mathrm{V}_{\mathrm{C}}+\Delta K$

(18)

Table4: Simulation parameters for Boost converter.

\begin{tabular}{|c|l|}
\hline Simulation parameters & \multicolumn{1}{c|}{ Values } \\
\hline DC- DC Boost & Input voltage $=31.16 \mathrm{~V}$ \\
converter & $\mathrm{C}_{1}=330 \mu \mathrm{F}$ \\
& $\mathrm{L}_{1}=2 \mathrm{mH}, 15 \mathrm{~A}$. \\
& $\mathrm{f}_{\mathrm{s}}=50 \mathrm{KHz}$ \\
\hline
\end{tabular}

By using the $\Delta V_{c}$, the duty cycle $\mathrm{D}$ is determined via the PWM block as shown in Figure 14 for the control of MOSFET in boost converter so as to realize the MPP search. The simulation parameters for boost converter is shown in Table 4.Simulink model of the Adaptive fuzzy MPPT 
control based photovoltaic power generation is shown in Figure 15.

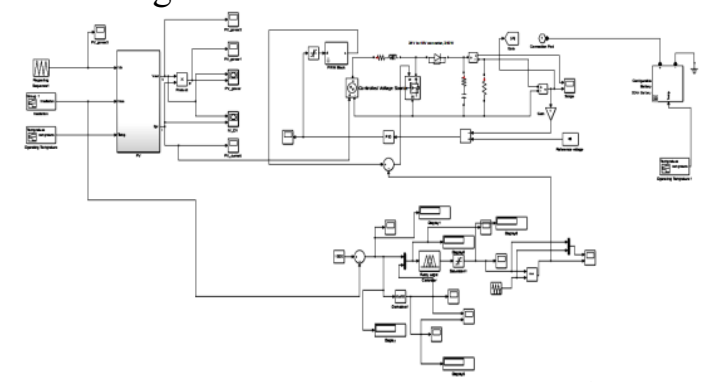

Figure 15. Simulink model of the adaptive fuzzy MPPT control based photovoltaic power generation.

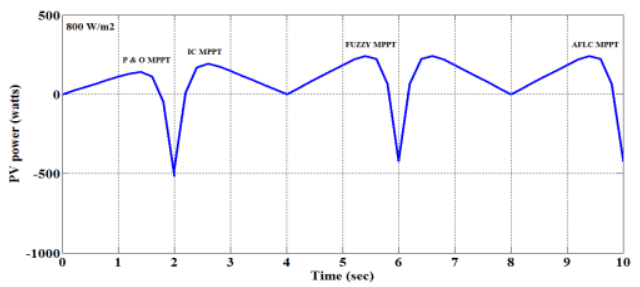

Figure $16 \mathrm{PV}$ power using various MPPT.

Figure 16 shows the $\mathrm{PV}$ power using $\mathrm{P} \& \mathrm{O}, \mathrm{IC}, \mathrm{FLC} \&$ AFLC. Using AFLC, for irradiance of $800 \mathrm{~W} / \mathrm{m}^{2}$, the obtained power value is about $240 \mathrm{~W}$, whereas it is $230 \mathrm{~W}$ for fuzzy logic control, $185 \mathrm{~W}$ for IC MPPT control, 165 $\mathrm{W}$ for P \& O MPPT control, the value of PV power is higher in AFLC compared to conventional.

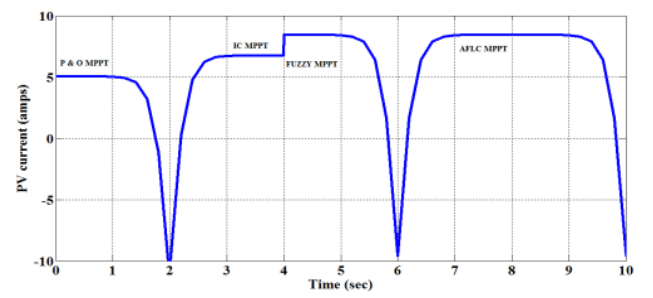

Figure 17. PV current using adaptive fuzzy logic MPPT.

Figure 17 shows the PV current using P\&O, IC, FLC \& AFLC. Using AFLC, for irradiance of $800 \mathrm{~W} / \mathrm{m}^{2}$, the obtained current value is about 8 $\mathrm{A}$, whereas it is $6.5 \mathrm{~A}$ for fuzzy logic control,5.8 A for IC MPPT control, 5 A for P \& O MPPT control, the value of PV current is higher in AFLC compared to conventional.

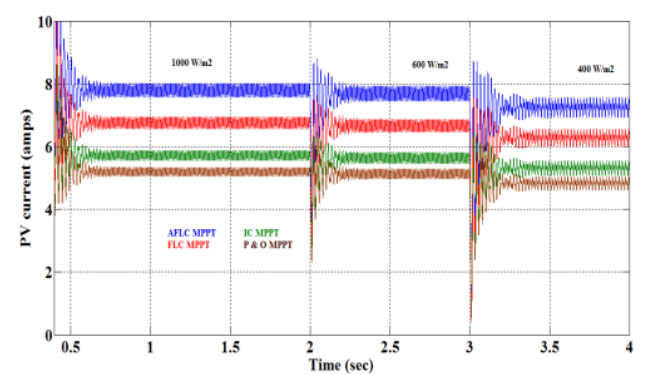

Figure 18. Converter current using adaptive fuzzy logic MPPT.

Figure 18 shows the converter current using P\&O, IC, FLC \& AFLC. Using AFLC, for irradiance of $1000 \mathrm{~W} / \mathrm{m}^{2}$, the obtained current value is about $8 \mathrm{~A}$, whereas it is $6.8 \mathrm{~A}$ for fuzzy logic control,5.8 A for IC MPPT control, 5 A for P \& O MPPT control, Similarly, for $600 \mathrm{~W} / \mathrm{m}^{2} \&$ $400 \mathrm{~W} / \mathrm{m}^{2}$, the value of converter current is higher in AFLC compared to conventional.

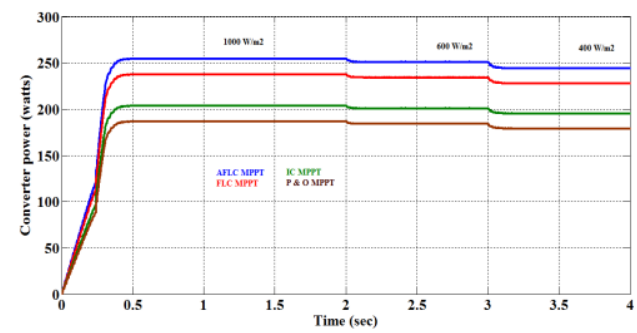

Figure 19. Converter power using adaptive fuzzy logic MPPT.

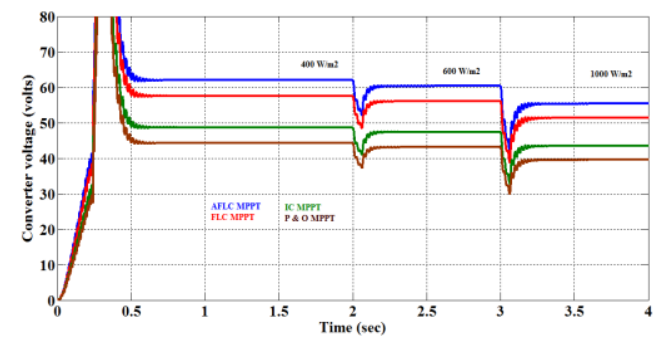

Figure 20. Converter voltage using adaptive fuzzy logic MPPT.

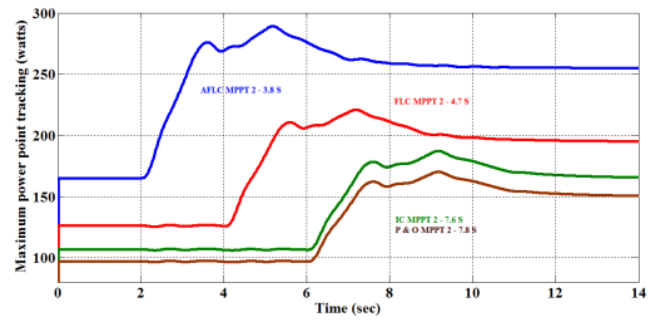

Figure 21. Time responses of boost voltage for various MPPT. 
Figure 19 shows the converter power using P\&O,IC,FLC \& AFLC. Using AFLC, for irradiance of $1000 \mathrm{~W} / \mathrm{m}^{2}$, the obtained power value is about $240 \mathrm{~W}$, whereas it is $230 \mathrm{~W}$ for fuzzy logic control, $185 \mathrm{~W}$ for IC MPPT control, $165 \mathrm{~W}$ for P \& O MPPT control, Similarly, for $600 \mathrm{~W} / \mathrm{m}^{2} \& 400 \mathrm{~W} / \mathrm{m}^{2}$, the value of converter power is higher in AFLC compared to conventional.

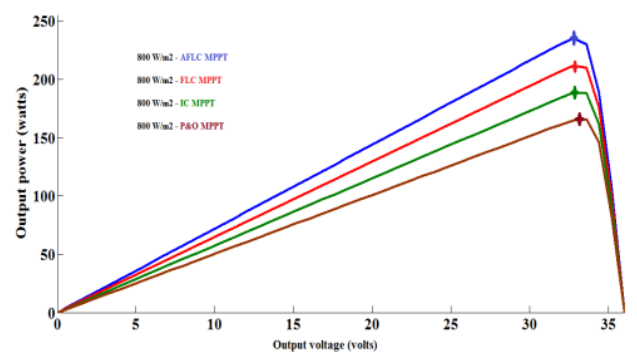

Figure 22. Converter output power for various MPPT.

Figure 20 shows the converter voltage using $\mathrm{P} \& \mathrm{O}, \mathrm{IC}, \mathrm{FLC} \& \mathrm{AFLC}$. Using AFLC, for irradiance of $400 \mathrm{~W} / \mathrm{m}^{2}$, the obtained voltage value is about $62 \mathrm{~V}$, whereas it is $58 \mathrm{~V}$ for fuzzy logic control, $50 \mathrm{~V}$ for IC MPPT control, $45 \mathrm{~V}$ for P \& O MPPT control, . Similarly, for $600 \mathrm{~W} / \mathrm{m}^{2} \&$ $1000 \mathrm{~W} / \mathrm{m}^{2}$, the value of converter voltage is higher in AFLC compared to FLC.

Figure 21 shows time responses when all four MPPT algorithms start to operate dc-dc converter to boost up the voltage output from 38 to $62 \mathrm{~V}$. The fastest response is achieved by the adaptive fuzzy algorithm in about $10 \mathrm{~ms}$, followed by the conventional FLC algorithm which is around 20 $\mathrm{ms}$, and the $\mathrm{P} \& \mathrm{O} \& \mathrm{IC}$ algorithm shows poor performance with about $40 \mathrm{~ms}$.

Figure 22 shows the converter output power for FLC, IC, P \& O \& AFLC. For irradiance of $800 \mathrm{~W} / \mathrm{m}^{2}$, the obtained power is about $240 \mathrm{~W}$ using AFLC method, whereas it is $210 \mathrm{~W}$ for fuzzy logic control, $180 \mathrm{~W}$ for IC control and 165 $\mathrm{W}$ for P \&O, which clearly depicts that AFLC accurately tracks the PV power compared to the conventional methods. Moreover, the results highlight that the tracking efficiencies of the PV system with AFLC under all operating conditions is higher compared to the classical techniques.

\section{Experimental setup for MPPT based photovoltaic system}

\author{
Table 5. Specifications of PV Panel \& Boost \\ Converter.
}

\begin{tabular}{|l|l|}
\hline Parameters & Values \\
\hline $\mathrm{V}_{\mathrm{oc}}$ & $31.16 \mathrm{~V}$ \\
\hline $\mathrm{I}_{\mathrm{sc}}$ & $8.57 \mathrm{~A}$ \\
\hline $\mathrm{P}_{\max }$ & $250 \mathrm{~W}$ \\
\hline Insolation $\mathrm{W} / \mathrm{m}^{2}$ & $1000 \mathrm{~W} / \mathrm{m}^{2}$ \\
\hline System efficiency & $76.72 \%$ \\
\hline Output Capacitance & $\mathrm{C}_{1}=330 \mu \mathrm{F}$ \\
\hline Inductance & $\mathrm{L}_{1}=2 \mathrm{mH}, 15 \mathrm{~A}$ \\
\hline Switching Frequency & $\mathrm{f}_{\mathrm{s}}=50 \mathrm{KHz}$ \\
\hline
\end{tabular}

The hardware set-up for the MPPT based PV system is shown in Figure 23. Photovoltaic panel and boost converter specifications are shown in Table 5.

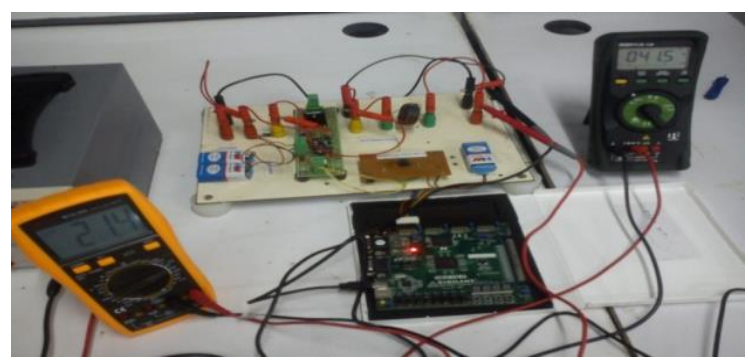

Figure 23. Hardware set-up for Boost converter for PV.

The experimental P-V and V-I characteristics are shown in Figure 24. The adaptive fuzzy MPPT have stable output waveforms as compared with conventional algorithm. High oscillation is observed from conventional algorithm and this oscillation may contribute to power losses. Figure 26 to Figure 28. shows time responses when all three MPPT algorithms start to operate dc-dc converter to boost up the voltage output from 38 to $62 \mathrm{~V}$. The fastest response is achieved by the adaptive fuzzy algorithm in about 10 micro second, followed by the conventional FLC algorithm which is around 30 micro sec, and the $\mathrm{P} \& \mathrm{O} \& \mathrm{IC}$ algorithm is the worst performance with about $40 \mathrm{~ms}$. The obtained experimental results are almost same as the results obtained from simulation works. 


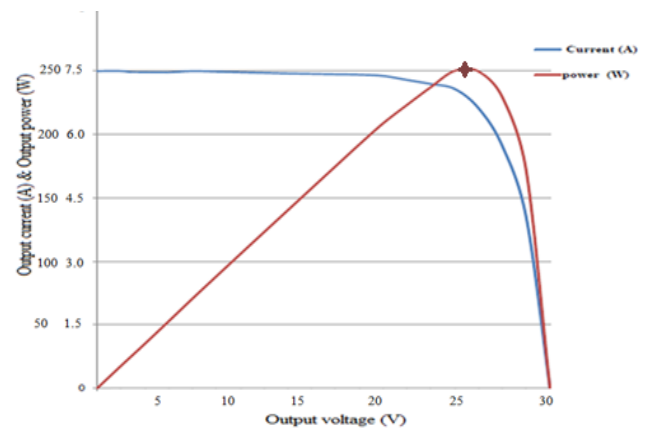

Figure24. Experimental P-V \& V-I characteristics.

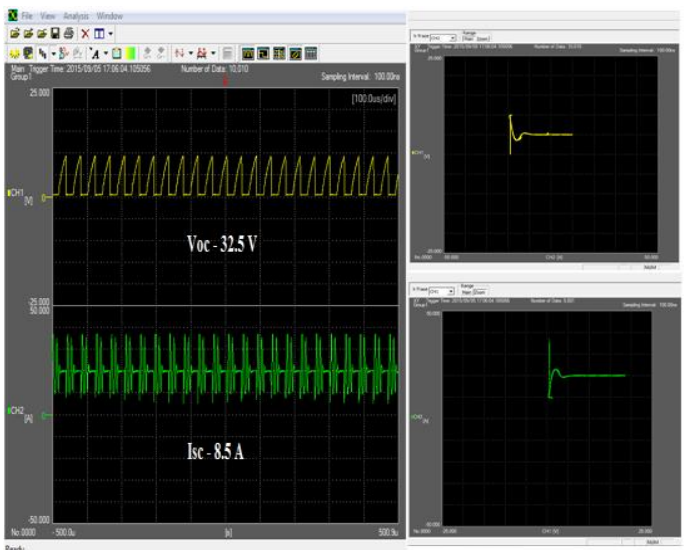

Figure 25. Experimental results for PV voltage and current.

The dynamic characteristics of PV array is measured using scope corder and it is shown in Figure $25\left(\mathrm{~V}_{\mathrm{OC}}=32.5 \mathrm{~V}\right.$ and $\left.\mathrm{I}_{\mathrm{SC}}-8.5 \mathrm{~A}\right)$.

The dynamic characteristics of PV current various MPPT is measured using scope corder and it is shown in Figure 29. The dynamic characteristics of PV voltage various MPPT is measured using scope corder and it is shown in Figure 30. Moreover, the results highlight that the tracking efficiencies of the PV system with AFLC based MPPT under all operating conditions is higher compared to the classical techniques.

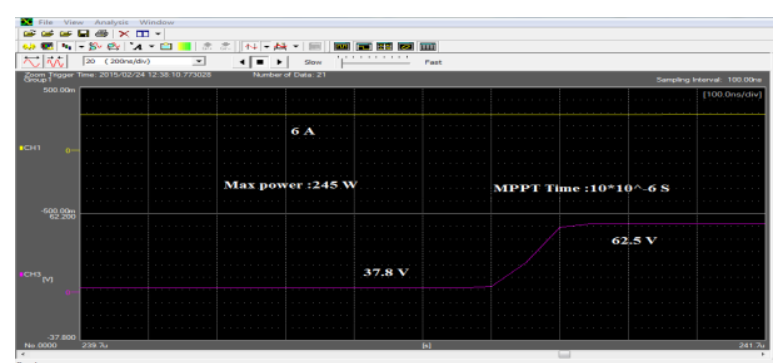

Figure 26: Time responses of boost voltage for a Adaptive fuzzy MPPT.

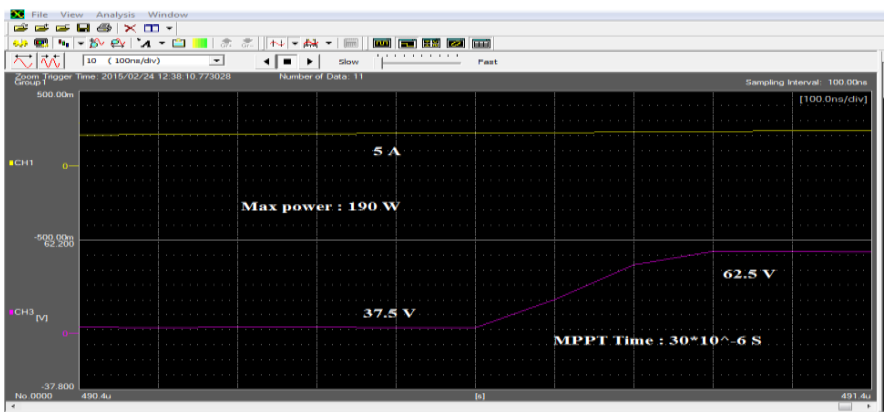

Figure 27:Time responses of boost voltage for a fuzzy MPPT.

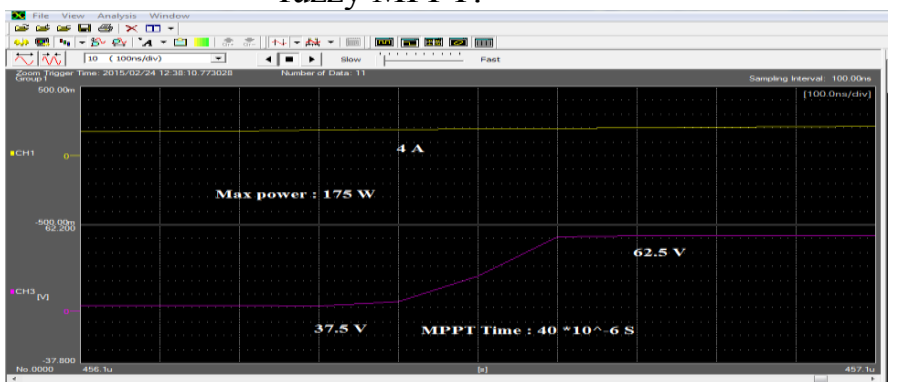

Figure 28. Time responses of boost voltage for a IC \& P\&O MPPT.

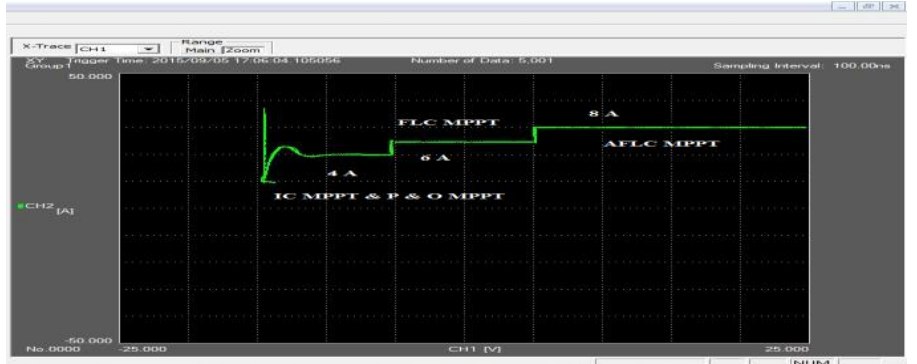

Figure 29. Experimental results for PV current various MPPT.

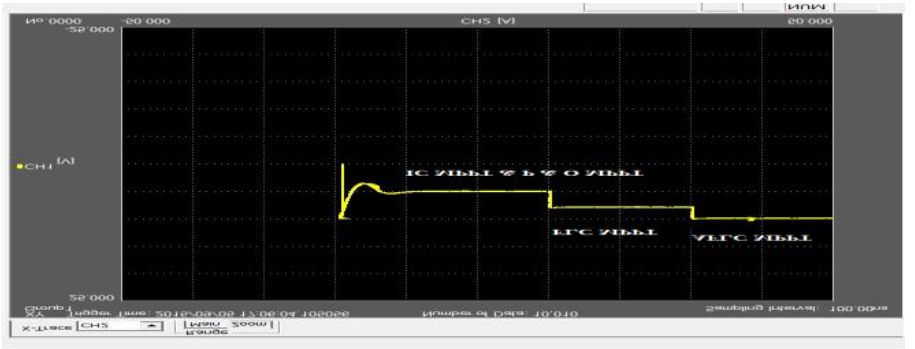

Figure 30. Experimental results for PV voltage of various MPPT.

\section{Conclusion}

This paper has reviewed the classical MPPT methods and proposed a new AFLC MPPT algorithm with the combination of adaptive and fuzzy control. This algorithm results in reduced complexity in its operation without compromising the performance. Wide range of irradiance level has been considered which 
contributes to the uniqueness of AFLC algorithm especially during operation at low irradiance. With AFLC, $95 \%$ of power is tracked under all operating conditions compared to the conventional methods .Moreover, AFLC is faster which is observed from the time response curve and it takes around only $10 \mathrm{~ms}$ to track the maximum power. Hence, it is concluded that AFLC algorithm is a better MPPT in terms of maximum power and tracking ability which is suited for photovoltaic systems.

\section{References:}

[1] Mei Shan Ngan and Chee Wei Tan, A Study of Maximum Power Point Tracking Algorithms for Stand-alone Photovoltaic Systems. IEEE applied power electronics colloquium, (IAPEC), pp .22-27, (2011).

[2] Salas, V, Olias, E, Barrado, A and Lazaro, A. ,Review of the maximum power point tracking algorithms for stand-alone photovoltaic systems . Solar Energy Materials \& Solar Cells, vol. 90, pp.1555-1578, (2006).

[3] Hohm, DP and Ropp, ME. ,Comparative Study of Maximum Power Point Tracking Algorithms using experimental, programmable, maximum power point tracking test bed', IEEE Photovoltaic specialist conference, pp. 1699-1702, (2000).

[4] Yanhong Kou, Yinshui Xia and Yidie Ye. , Fast variable step-size maximum power point tracking method for photovoltaic systems . Journal of Renewable and Sustainable Energy, vol. 7, no. 4, pp. 321-329, (2015).

[5] Lalouni, S Rekioua, D Rekioua, T and Matagne, E. , Fuzzy logic control of stand-alone photovoltaic system with battery storage. Journal of Power Sources, vol. 193, no. 2 pp. 899-907, (2009).

[6] Mohamed Farahat, A Mohamed Enany, A and Ahmed Nasr. , Assessment of maximum power point tracking techniques for photovoltaic system applications. Journal of Renewable and Sustainable Energy, vol. 7, no. 4, pp. 568-585, (2015).
[7] Soubhagya Kumar Dash, Savita Nema, Nema, RK and Deepak Verma, A comprehensive assessment of maximum power point tracking techniques under uniform and non-uniform irradiance and its impact on photovoltaic systems. A review. Journal of Renewable and Sustainable Energy, vol. 7, no. 6, pp. 260-272, (2015).

[8] Pallavee Bhatnagar, A and Nema, BRK. , Conventional and global maximum power point tracking techniques in photovoltaic applications: A review. Journal of Renewable and Sustainable Energy vol. 5, no. 3, pp. 689-692, (2013).

[9] Hadeed Ahmed Sher, Ali Murtaza, F Abdullah Noman, Khaled Addoweesh, E and Marcello Chiaberge, An intelligent control strategy of fractional short circuit current maximum power point tracking technique for photovoltaic applications. Journal of Renewable and Sustainable Energy, vol. 7, no. 1, pp. 448-460, (2015).

[10] Jiyong Li and Honghua Wang, Maximum Power Point Tracking of Photovoltaic Generation Based on the Fuzzy Control Method. IEEE international conference on sustainable power generation and supply, pp. 1-6, (2009).

[11] Yeong-Chau Kuo, Tsomg-Juu Liang and Jiann-Fuh Chen ,Novel Maximum Power Point Tracking Controller for Photovoltaic Energy Conversion System. IEEE Transactions on Industrial Electronics, vol. 48, no. 3, pp. 594-601, (2001).

[12] Yinqing Zou, Youling $\mathrm{Yu}, \mathrm{Yu}$ Zhang and Jicheng Lu, MPPT Control for PV Generation System Based on an Improved Incremental conductance Algorithm. International workshop on Information and Electronics Engineering, vol. 29, pp. 105-109, (2012).

[13] Ahmad Al-Diab and Constantinos Sourkounis, Variable Step Size P\&O MPPT Algorithm for PV Systems. 12th International Conference on Optimization of Electrical and 
Electronic Equipment, (OPTIM),pp. 1097-1102, (2010).

[14] Chekired, F, Larbes, C, Rekioua, $\mathrm{D}$ and Haddad, F, Implementation of a MPPT fuzzy controller for photovoltaic systems on FPGA circuit. International conference on MEDGREEN, vol. 6, pp. 541-549, (2011).

[15] Bouchafaa, F Hamzaoui, I and Hadjammar. , Fuzzy Logic Control for the tracking of maximum power point of a PV system. International conference MEDGREEN, Energy Procedia, vol. 6, pp. 633-642, (2011).

[16]Balasubramanian, G and Singaravelu, S. , Fuzzy logic controller for the maximum power point tracking in photovoltaic system. International Journal of Computer Applications, vol. 41, no.12, pp. 22-28, (2012).

[17] Eftichios Koutroulis, Kostas Kalaitzakis and Nicholas Voulgaris, C. , Development of a MicrocontrollerBased, Photovoltaic Maximum Power Point Tracking Control System. IEEE transactions on power electronics, vol. 16, no. 1, pp. 46-54, (2001).

[18] Khaehintung N, Wiangtong $\mathrm{T}$ and Sirisuk, P. , FPGA Implementation of MPPT Using Variable Step-Size P\&O Algorithm for PV Applications. IEEE International Symposium on Communications and Information technologies, vol. 06, pp. 212-215, (2006).

[19] Mekki H, Mellit A, Kalogirou SA, Messai, A and Furlan, G. , FPGABased implementation of a real time photovoltaic module simulator. Progress in Photovoltaics: Research and Application,

vol. 18, no. 2, pp. 115-127, (2010).

[20] Messai, A. Mellit, A. Guessoum, A and Kalogirou, SA., Maximum power point tracking using a GA optimized fuzzy logic controller and its FPGA implementation. Journal of Solar energy, vol. 85, no. 2, pp. 265-277, (2011).

[21] Salmi, T, Bouzguenda, M, Gastli, A and Masmoudi, A. ,
Matlab/Simulink based modelling of solar photovoltaic cell. International Journal of Renewable Energy Research, vol. 2, no. 2, pp. 213-218,(2012).

[22] Shimi Sudha Letha, Tilak Thakur, Jagdish Kumar, Dnyaneshwar Karanjkar and Santanu Chatterji. , Design and Real Time Simulation of Artificial Intelligent Based MPP Tracker for Photo-Voltaic System. ASME International mechanical engineering congress and exposition, vol. 6, no. 2,pp. 11-20, (2014).

[23] Averbukh, M, Ben-Galim, Y and Uhananov, A., Development of a Quick Dynamic Response Maximum Power Point Tracking Algorithm for Off-Grid System With Adaptive Switching (OnOff) Control of dc/dc Converter. Journal Solar Energy Engineering, vol. 135, no. 2,pp. 1268-1279,(2012).

[24] Seung Hoe Choi, Jin Hee Yoon, Fuzzy Regression Based on NonParametric Methods, WSEAS Transactions on Systems and Control, pp. 20-25, Volume 13, 2018.

[25] Dzenan Gusic, Sanela Nesimovic Automatization in Vague Database Relations via Lukasiewicz Fuzzy Implication Operator, WSEAS Transactions on Systems and Control, pp. 445-459, Volume 14, 2019.

\section{Creative Commons Attribution License 4.0 (Attribution 4.0 International, CC BY 4.0)}

This article is published under the terms of the Creative Commons Attribution License 4.0

https://creativecommons.org/licenses/by/4.0/deed.en US 